\title{
An efficient mechanical-probabilistic approach for the collapse modelling of RC structures
}

\section{Uma abordagem mecano-probabilística eficiente para a modelagem do colapso de estruturas em concreto armado}
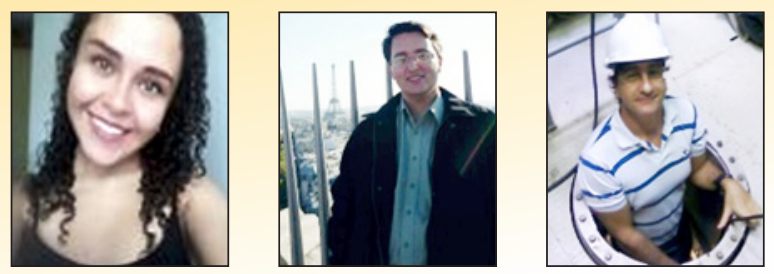

К. O. COELHO karolinneoc@gmail.com https://orcid.org/0000-0002-3088-9977

E. D. LEONEL a edleonel@sc.usp.br https://orcid.org/0000-0002-7842-0334

J. FLÓREZ-LÓPEZ b julio.lopez@unila.edu.br https://orcid.org/0000-0001-6882-4741

\begin{abstract}
The reinforced concrete $(R C)$ structures are widely utilized around the world. However, the modelling of its complex mechanical behaviour by efficient numerical approaches has been presented marginally in the literature. The efficient approaches enable the accurate and the realistic representation of the mechanical phenomena involved and are computationally efficient for analysing complex structures. In the present study, the improved version of the lumped damage model is coupled to the Monte Carlo simulation method to represent the mechanical-probabilistic behaviour of RC structures. In such model, the concrete cracking and reinforcements' yield are represented accurately. Moreover, this damage approach enables the accurate modelling of failure scenarios, which are based on the damage variable. Furthermore, this coupled model enables the determination of the collapse modelling accounting for uncertainties, which is the main contribution of the present study. One simple supported $\mathrm{RC}$ beam and one 2D RC frame are analysed in the probabilistic context. The accurate results are obtained for the probabilistic collapse path as well as its changes as a function of the loading conditions and material properties uncertainties.
\end{abstract}

Keywords: lumped damage model, probabilistic collapse modelling, safety assessment, hyperstatic structures.

\section{Resumo}

As estruturas em concreto armado são largamente utilizadas ao redor do mundo. Entretanto, a modelagem de seu complexo comportamento mecânico por formulações numéricas eficientes tem sido marginalmente apresentada na literatura. As formulações eficientes possibilitam a precisa e realista representação dos fenômenos mecânicos envolvidos e são computacionalmente eficientes para a análise de estruturas complexas. Nesse estudo, uma versão aprimorada do modelo de dano concentrado é acoplada ao método de simulação de Monte Carlo para a representação do comportamento mecano-probabilístico de estruturas em concreto armado. Nesse modelo, a fissuração do concreto e o escoamento da armadura são representados com precisão. Além disso, essa formulação de dano possibilita a modelagem precisa de complexos cenários de falha, os quais são baseados na variável de dano. Não obstante, esse modelo acoplado possibilita a determinação da modelagem do colapso levando em consideração as incertezas, a qual é a principal contribuição desse estudo. Uma viga simplesmente apoiada e um pórtico bidimensional, ambos em concreto armado, são analisados no contexto probabilístico. Resultados realistas são obtidos para a determinação do caminho de falha mais provável, assim como para suas alterações em função das condições de carregamento e incertezas associadas às propriedades materiais.

Palavras-chave: modelo de dano concentrado, modelagem probabilística do colapso, avaliação da segurança, estruturas hiperestáticas. 


\section{Introduction}

The reinforced concrete $(R C)$ is the most utilized structural system in the world. The coupling between steel and concrete enables the engineers to propose composite structures accounting for complex architectural geometries and fair costs. In the past decades, the $\mathrm{RC}$ design aimed at coupling the mechanical performance with the minimum material consuming. Recently, many efforts have been dedicated for incorporating properly the mechanical uncertainties and the failure consequences into the structural design, as observed into the Performance-Based Design, for instance. For the general case, accurate and realistic mechanical models are required. In addition, such models should present efficient performance to enable the reliable coupling with probabilistic approaches (Afroughsabet et al. [1]; Carpinteri [2]).

The scientific community has accumulated significant knowledge on the mechanical behaviour of RC structures, especially when mechanical degradation and collapse modelling are the focus (Oliveira and Leonel [3]; Desmorat et al. [4]; Matallah and La Borderie [5]). Within the framework of continuum damage mechanics, the damage approach developed by Mazars [6] is one of the most frequently utilized in the inelastic analyses of RC structures. Despite being a simplified approach, the mechanical modelling based on the Mazars damage provides accurate results, as described in the literature (Légeron et al. [7]; Junior and Venturini [8]). However, this damage model requires a very fine longitudinal discretization, and, additionally, the division of the cross-section into layers, where each one of them represents the mechanical behaviour either the steel or concrete, even for common RC elements. To perform complex inelastic analyses in RC structures, simplified models are utilized as long as they do not lose the representativeness of the phenomena involved. In this context, the lumped damage mod$\mathrm{el}$ is an alternative approach to the classical continuum damage mechanics models. This approach consists on the coupling of the damage mechanics and the fracture mechanics concepts into the plastic hinge idea (Flórez-López et al. [9]). The damage is incorporated into the plastic hinges, which becomes general inelastic hinges. This mod$\mathrm{el}$, although simpler, is efficient and provides results as accurate as those achieved by complex and refined constitutive approaches. In addition to its accuracy, the excellent computational efficiency of the lumped damage model enables its application into complex inelastic analyses, which involves hyperstatic structures, 3D frames, cyclic or impact loadings. Therefore, such characteristics make the lumped damage model suitable for the coupling with reliability methods, which requires several mechanical model runs to achieve the probability of failure. Several studies presented in the literature demonstrate the successfully application of the lumped damage mechanics in various types of structures (Cipollina et al. [10]; Flórez-López [11]; Rajasankar et al. [12]). In addition to them, it is worth citing the application of this approach in 2D frames, 3D frames and arches (Alva and El Debs [13]; Marante and Flórez-López [14]; Amorim et al. [15]). Similarly, this model enables accurate results for cyclic loadings, high cycle fatigue, impact loads or explosion (Febres et al. [16]).

In spite of these important advances, the above-mentioned developments accounted only for the deterministic aspects of the phenomena. However, the practical observations reveal that the structural dimensions, the material properties and loading values possess inherent uncertainties. Therefore, to describe realistically the phenomena involved the randomness must be accounted. The randomness is considered by describing the parameters formulation by individual statistical distributions. Because the parameters randomness are accounted, the mechanical response presents probabilistic characteristic (Nowak and Collins [17]). Therefore, such problem is only properly analysed in the context of reliability theory. In recent years, many efforts have been dedicated to the development of reliability methods and algorithms (Sankararaman [18]; Sun et al. [19]; Straub [20]). However, the coupling of these approaches to efficient and robust mechanical models are presented marginally in the literature (Liberati et al. [21]; Leonel et al. [22]), which justifies the development of the present study. In the literature, some probabilistic approaches have been proposed to handle the safety analysis of RC structures. Among them, it is worth citing Frangopol et al. [23], which analysed RC columns, and Neves et al. [24], where RC grids were modelled.

It is worth mentioning that the probability of structural failure is assessed with the failure scenarios identified by the mechanical models. Therefore, the accurate and the consistent probabilistic modelling is feasible as long as realistic and robust mechanical models are utilized. However, the modelling of the complex structural behaviour often need elaborate formulations and numerical models, which also requires large computational time consuming. Thus, such limitation may impedes general mechanical-probabilistic couplings. The robust coupled model must be capable to achieve the probability of failure and the variables sensitivity with reduced computational time consuming. When expensive mechanical models are utilized, alternative strategies, such as the metamodeling, may be applied for the proper computational cost.

In the present study, the coupled mechanical-probabilistic model is proposed for the inelastic analyses of RC structures accounting for uncertainties. The improved version of the lumped damage model was implemented into a finite element platform, which considers the 2D frame finite element. Initially, the numerical model was utilized in the simulation of one RC beam and one 2D RC frame, which were previously analysed numerically and experimentally in other researches available in the literature (Alvarez [25]; Nogueira et al. [26]; Vecchio and Collins [27]). Afterwards, these structures were analysed accounting for the randomness.

The coupling procedure between the efficient/robust mechanical model for inelastic analyses of RC structures and the reliability approach is one contribution of the present study. Because of the computational efficiency of the lumped damage model, such approach is coupled to the Monte Carlo simulation method without any metamodeling approach. Thus, this type of coupling leads to the accurate results because the mechanical responses required by the reliability method are obtained directly from the mechanical model. Moreover, the coupled model accounts accurately for the efforts redistribution during the material damage. Therefore, the proposed model represents accurately the probabilistic collapse because the limit states required by the probabilistic approach are accurately identified. Then, this coupled model enables the determination of the structural collapse configuration accounting for uncertainties, which is the major contribution of this study. 


\section{The improved lumped damage formulation}

The inelastic formulation for the RC elements assumes the damage localized at the element ends. Thus, the concrete cracking and the reinforcements' yielding are assumed to occur at the element ends as illustrated in Fig. (1). The plasticity phenomenon associated to the steel rebar is represented through the formation of plastic hinges. As a result, the damage variables are added to the plastic hinges $\left(d_{i}, d_{j}\right)$, which are generally named as inelastic hinges.

Firstly, the inelastic hinges accumulate the concrete degradation through the damage index. During the bending moment increase, the plastic moment is achieved and the rebar's yielding effects are added to the inelastic hinges. Thus, the inelastic hinges incorporate the two inelastic effects observed in RC structures: the damage propagation due to the concrete cracking and the plastic hinge formation due to the rebar yielding. Two evolution laws represent such mechanical effects: the damage law and the plastic deformation evolution law. The coupling of these two effects into the inelastic hinges leads to the accurate mechanical collapse modelling of RC structures.

The generalized strains in this structural element is represented by the matrix $\Phi$ as follows:

$\{\Phi\}=\left\{\begin{array}{lll}\phi_{i} & \phi_{j} & \delta\end{array}\right\}^{T}$

in which $\phi_{i}$ e $\phi_{j}$ represent the relative rotations and $\delta$ is the elongation of the element, as illustrated in Fig. (2). In the finite element method (FEM) context, the nodal parameters introduced in Eq. (1) are interpolated by shape functions along the element length.

The matrix $\Phi$ introduced in Eq. (1) is split into its elastic, $\Phi_{\mathrm{e}}$, plastic, $\Phi_{\mathrm{p}}$, and damage, $\Phi_{\mathrm{d}}$, parts. The strain equivalent hypothesis validates this operation. Therefore, $\Phi$ is rewritten as follows:

$\{\Phi\}=\left\{\Phi_{e}\right\}+\left\{\Phi_{p}\right\}+\left\{\Phi_{d}\right\}$

The reinforcements' yielding and the concrete cracking generate relative displacements and rotations in the structure. Therefore, the mechanical damage evolution is assessed through the generalized stresses and strains, which are connected by kinematic relations, equilibrium relations and constitutive laws. The
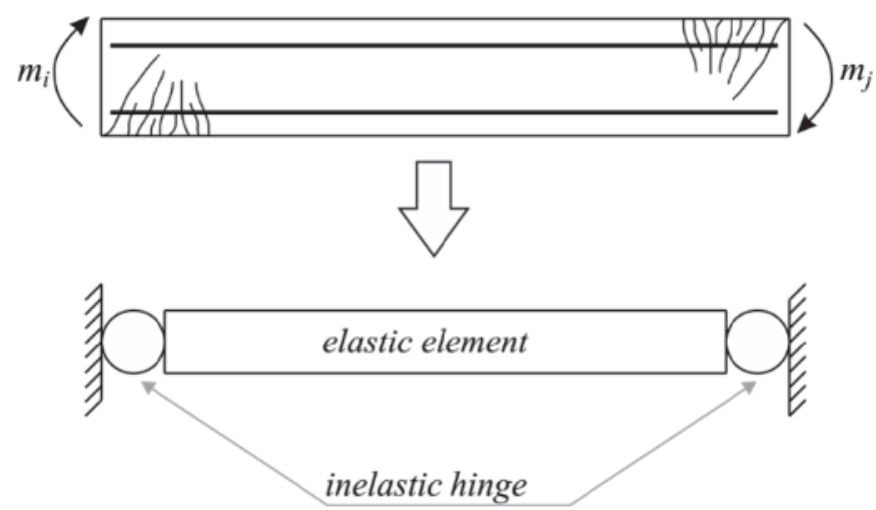

Figure 1

Finite element of RC and the corresponding model of lumped damage

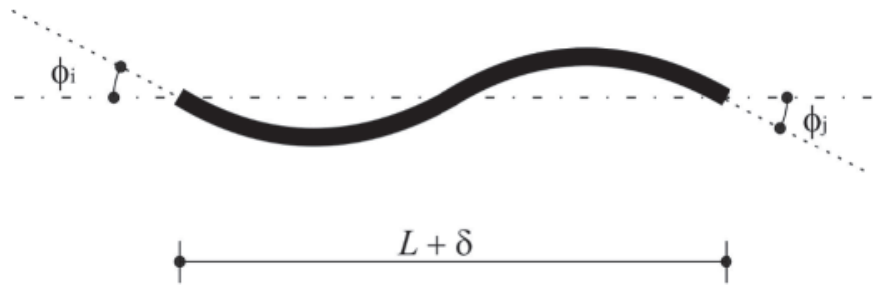

Figure 2

Generalized strains of the finite element

latter considers the evolution laws for damage and plasticity. The Fig. (3) presents a flowchart, which describes the required steps for the mechanical analysis based on the lumped damage model. The respective relationships are presented in the following.

In the FEM context, the lumped damage model is implemented considering the $2 \mathrm{D}$ frame structure. The element has six degrees of freedom, three for each at the two nodes of the element: horizontal displacement $u$, vertical $w$ and rotation $\theta$. The generalized displacement matrix is proposed as follows:

$\{U\}=\left\{\begin{array}{llllll}u_{i} & w_{i} & \theta_{i} & u_{f} & w_{f} & \theta_{f}\end{array}\right\}^{T}$

in which $i$ and $f$ indicate the initial and final element nodes, respectively. The generalized displacements and strains are connected through the kinematic equations, which are obtained by geometrical considerations. For the $2 \mathrm{D}$ frame structure, these variables are connected as follows:

$\{\Delta \Phi\}=\left[B_{0}\right]\{\Delta U\}$

The matrix $\left[\mathrm{B}_{0}\right]$ indicates the kinematic transformation, which is the following Flórez-López et al. [9]:

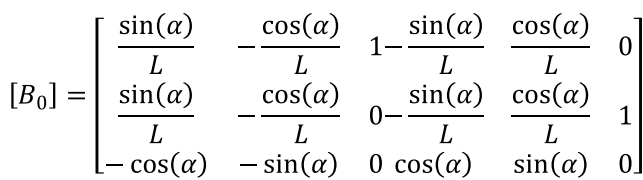

in which $\alpha$ is the angle between the horizontal direction and the element axis.

The equilibrium equation, neglecting the geometrical nonlinear and inertia effects, is written as follows:

$\left[B_{0}\right]^{T}\{M(t)\}=\{P(t)\}$
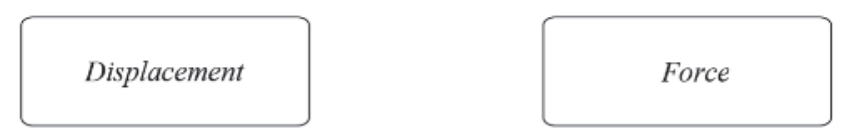

Kinematic

Equilibrium
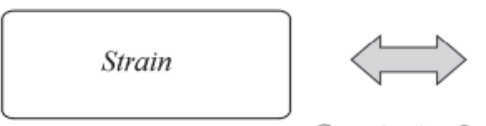

Stress

Constitutive Law

Damage and Plasticity

Figure 3

Flowchart for the lumped damage analysis 
where $P$ represents the nodal force vector. The vector $M(t)$ represents the generalized stress, which is conjugated with $\Phi$. The $M(t)$ vector includes the bending moments at the element ends and the normal force. Thus, this vector is defined as follows:

$\{M(t)\}=\left\{\begin{array}{lll}m_{i}(t) & m_{j}(t) & n(t)\end{array}\right\}^{T}$

The constitutive law relates generalized strains and stresses through the flexibility matrix (Flórez-López et al. [9]). Thus:

$\left\{\Phi-\Phi_{p}\right\}=[F(D)]\{M\}+\left(\Phi_{0}\right)$

where $[F]$ is the flexibility matrix of the damaged element and $\left\{\Phi_{0}\right\}$ is the vector of initial strains.

The flexibility matrix of the damaged element is assessed by considering the strain equivalence hypothesis. Thus:

$[F(D)]=\left[F_{0}\right]+[C(D)]$

in which $\left[F_{0}\right]$ is the flexibility matrix for the elastic element and $[C(D)]$ represents the additional flexibility caused by the concrete cracking.

To account for the mechanical damage, the damage variables at the element ends, $d_{i}$ and $d_{i}$, must be included. Thus, the introduction of the damage variables into the $2 \mathrm{D}$ frame flexibility matrix leads to the following:

$[F(D)]=\left[\begin{array}{ccc}\frac{L}{3 E I\left(1-d_{i}\right)} & -\frac{L}{6 E I} & 0 \\ -\frac{L}{6 E I} & \frac{L}{3 E I\left(1-d_{j}\right)} & 0 \\ 0 & 0 & \frac{L}{E A}\end{array}\right]$

The damage evolution law is based on the energy criterion formulated by Griffith. Such criterion introduces the energy release rate during the crack propagation as the derivative of the complementary energy with respect to the damage parameters. For the $2 \mathrm{D}$ frame element, the strain energy is defined as follows (Marante and Flórez-López [14]):

$W_{b}=\frac{1}{2}\{M\}^{T}\left\{\Phi-\Phi_{p}\right\}=\frac{1}{2}\{M\}^{T}[F(D)]\{M\}+\frac{1}{2}\{M\}^{T}\left\{\Phi_{0}\right\}$

Therefore, the energy release rates for the hinges $i$ and $j$ are defined as follows:

$G_{i}=\frac{\partial W_{b}}{\partial d_{i}}=\frac{L m_{i}^{2}}{6 E I\left(1-d_{i}\right)} \quad G_{j}=\frac{\partial W_{b}}{\partial d_{j}}=\frac{L m_{j}^{2}}{6 E I\left(1-d_{j}\right)}$

The damage evolution law is obtained by balancing the energy release rate with the crack resistance at the inelastic hinge. Such comparison establish nil damage variation if the energy release rate is smaller than the crack resistance. For positive damage increments, the energy release rate and the crack resistance have correspondent values. Thus, the damage evolution is defined as follows:

$$
\left\{\begin{array} { l l } 
{ \Delta d _ { i } = 0 , } & { \text { if } G _ { i } < R _ { i } } \\
{ G _ { i } = R _ { i } , } & { \text { if } \Delta d _ { i } > 0 }
\end{array} \quad \left\{\begin{array}{ll}
\Delta d_{j}=0, & \text { if } G_{j}<R_{j} \\
G_{j}=R_{j}, & \text { if } \Delta d_{j}>0
\end{array}\right.\right.
$$

The resistance against the crack propagation is represented by a resistance criterion. Such criterion is defined according to experimental analyses, which relate this parameter to the damage variable. For the general case, such criterion is expressed as following (Flórez-López et al. [9])]:

$R(d)=R_{0}+q \frac{\ln (1-d)}{1-d}$ where $R_{0}$ represents the initial mechanical resistance. The second term of the previous equation describes the gain into the mechanical resistance due to the presence of the reinforcements, which hinders the crack propagation.

The parameters $R_{0}$ and $q$ depend on the geometrical and mechanical characteristics of the structural element. These parameters are evaluated from the first cracking bending moment $\left(\mathrm{M}_{\mathrm{cr}}\right)$ and the ultimate bending moment $\left(\mathrm{M}_{\mathrm{u}}\right)$ for the desired cross-section. The connection between the damage variable and the bending moment is performed by equalling the $G$ to $R$. Such operation leads to the following expression:

$m^{2}=\frac{6 E I(1-d)^{2}}{L} R_{0}+\frac{6 q E I}{L}(1-d) \ln (1-d)$

The dependence between the damage variable and the bending moment introduced in Eq.(15) is illustrated in Fig (4).

When the applied bending moment reaches the ultimate bending moment, nil damage increment value at the hinge is assumed. Therefore, the $R_{0}$ value is as follows:

$R_{0}=\frac{M_{c r}^{2}}{6 E I} L$

The $q$ is expressed as a function of the ultimate bending moment and its respective damage value. The inflexion point at the curve illustrated in Fig. (4) determines the ultimate damage value. Thus, such point is determined by deriving the function introduced in Eq. (15) with respect to the damage variable and equalling it to zero.

The plastic strain evolution laws according to Flórez-López et al. [9] is defined as follows:

$\left\{\begin{array}{l}d \phi_{p i}=0, \quad \text { if } f_{i}<0 \\ f_{i}=0, \quad \text { if } d \phi_{p i} \neq 0\end{array} \quad\left\{\begin{array}{l}d \phi_{p j}=0, \quad \text { if } f_{j}<0 \\ f_{j}=0, \quad \text { if } d \phi_{p j} \neq 0\end{array}\right.\right.$

The yield function, $f$, accounts for the damage and the kinematic hardening. The equivalent bending moment and the hypothesis of equivalence of strains enables writing the yield function as follows (Flórez-López et al. [9]):

$f=\left|\frac{m}{1-d}-c \phi_{p}\right|-k_{0}$

where $c$ and $k_{0}$ are element-dependent constants.

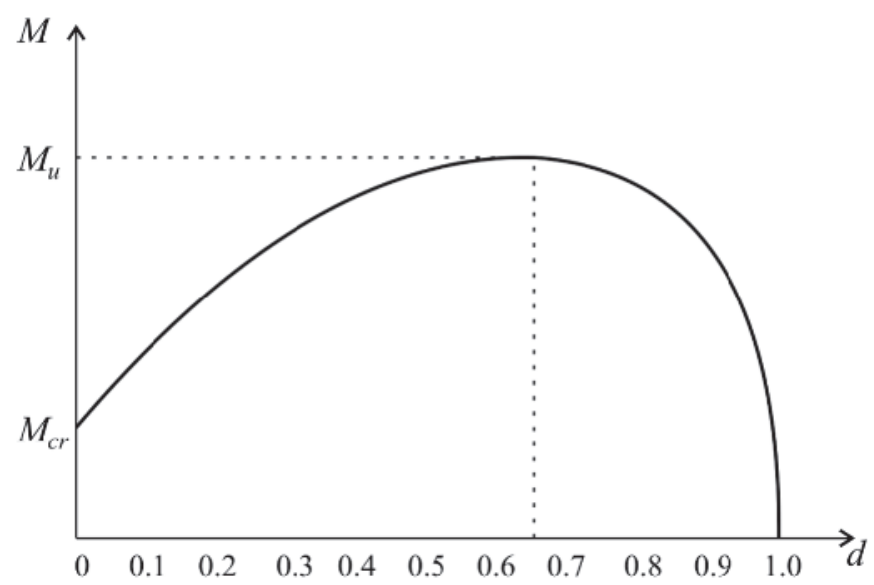

Figure 4

Bending moment as a function of damage 
In RC structures, the cracking bending moment is smaller than the yield bending moment. Thus, the values of $c$ and $k_{0}$ are assessed as a function of the yield damage $d_{p}$ through the aforementioned Eq. (15). When the yield damage value is reached, the plastic rotation is assumed as nil as well as its increment value into the yield function. Therefore, $k_{0}$ become the effective yield moment. Thus:

$k_{0}=\frac{M_{p}}{1-d_{p}}$

The yield function is also equal to zero when the ultimate bending moment is reached. Therefore, the assessment of the coefficient $c$ as a function of the ultimate plastic rotation leads to the following:

$c=\frac{1}{\phi_{p u}}\left(\frac{M_{u}}{1-d_{u}}-\frac{M_{p}}{1-d_{p}}\right)$

The lumped damage model, as presented above, assumes that damage and plasticity effects occur only at the element ends, i.e., at the inelastic hinges. However, in many structural systems and loading conditions, the mechanical damage observed cannot be accurately represented by such hypotheses. For instance, frame elements subjected to constant bending moments, as observed in the four point bending test, observes the distributed damage condition. Therefore, this situation is not accomplishable through the original formulation of the lumped damage model. To overcome such limitation, this study proposes an improvement over the classical lumped damage model. To account for distributed damage cases, the element stiffness required by the damage model has to be penalized through the crosssectional inertia. Thus, in this case, the cross-sectional inertia has to be smaller than the utilized by the damage formulation. This study proposes that such penalization follows the ACI 318-08 [28] recommendations, in which the effective cross-sectional inertia of a cracked cross-section $\left(I_{\text {ef }}\right)$ be a function of the bending moment $(m)$ and the cracking bending moment $\left(M_{c r}\right)$. Thus, following [28] one has:

$I_{e f}=\left(\frac{M_{c r}}{m}\right) I_{e q}+\left[1-\left(\frac{M_{c r}}{m}\right)^{3}\right] I_{u l t}$

where $I_{e q}$ is the cross-section inertia assuming the complete crosssection dimensions and $I_{u l t}$ is the cross-sectional inertia relative to the ultimate moment, which is given by Eq. (22).

$I_{u l t}=b d_{k}^{3}\left[\frac{1}{2} k^{2}\left(1-\frac{k}{3}\right)+\eta \rho \beta_{c}\left(k-\frac{d_{k}^{\prime}}{d_{k}}\right)\left(1-\frac{d_{k}^{\prime}}{d_{k}}\right)\right]$

where $b$ is the cross-section width, $n$ is the ratio of Young modulus from concrete and steel, $d_{k}$ and $d_{k}$ 'represent the distance of the tension $\left(A_{s}\right)$ and compression rebar area $\left(A_{s}^{\prime}\right)$ to the top surface, respectively. The neutral axis location, ( $k$ ), is given by Eq. (23) and $\beta_{c}$ is the coefficient related to the steel rate obtained by the Eq. (24).

$k=\sqrt{(\eta \rho)^{2}\left(1+\beta_{c}\right)^{2}+2 \eta \rho\left(1+\beta_{c} \frac{d_{k}^{\prime}}{d_{k}}\right)}-\eta \rho\left(1+\beta_{c}\right)$

$\beta_{c}=\frac{(1-\eta) \rho^{\prime}}{\eta \rho}$

$\rho$ and $\rho^{\prime}$ indicate the rate of tension and compression rebar, calculated as follows:

$\rho=\frac{A_{s}}{b d} \quad \rho^{\prime}=\frac{A_{s}^{\prime}}{b d}$
Because the cross-sectional inertia is penalized, the structural element stiffness is also penalized. In spite of being a simpler proposition, this penalization over the cross-sectional inertia represents a contribution, even that by a slight amount, for the lumped damage models, which can now account consistently for distributed damage cases. The results presented in this study illustrate the efficiency of the proposed improvement.

\section{Reliability approach}

\subsection{The probabilistic problem}

The reliability methods enable the assessment of the probability of failure, $P_{f}$, considering specific failure scenarios, which are named as the limit states. In this type of analysis, the set of random variables $X=\left[X_{1}, X_{2}, \ldots, x_{n}\right]$ ${ }^{\top}$ has to be initially identified. Then, individual probability distributions are attributed to such variables for modelling its randomness. Afterwards, the failure modes must be defined. Thus, a limit state function, $G(X)$, for each failure mode is defined in order to separate the random space into two domains: the safe domain, with $G(X)>0$, and the failure domain, where $G(X)<0$. The interface between the safe and the failure domains, $G(X)$ $=0$, is named as the limit state itself. Therefore, the probability of failure in the structural context can be defined as the probability of the structural system do not accomplish one or more than one design requirements. It is worth mentioning that explicit forms for the limit state functions are not usually available in complex structural problems. When numerical models represent the mechanical behaviour, solely the limit state function values are known at an informed amount of points.

The probability of failure is assessed by the integration of the joint density function along the failure domain (Cristensen and Baker [29]). Therefore, the probability of failure is evaluated as follows:

$P_{f}=\int_{G \leq 0} f_{x}\left(x_{1}, x_{2}, \ldots, x_{n}\right) d x_{1} d x_{2}, \ldots, d x_{n}$

in which: $f_{x}(X)$ is the joint density function of the random variables $X$. The explicit assessment of Eq. (26) for complex engineering problems is impossible because the limit state function and consequently the failure and safe domains descriptions are implicit. Therefore, for such cases, this integral is evaluated by simulation techniques. The most important simulation technique is the Monte Carlo simulation method. This simulation technique requires wide range of sampling for achieving the accurate results. Consequently, non-efficient numerical mechanical models lead to the unreliable coupling approaches. Nevertheless, this study proposes the coupling between the lumped damage model and the Monte Carlo simulation method. This coupled model is accomplishable due to the excellent computational efficiency of the lumped damage approach, even in complex structural systems.

In the present study, the limit state functions are defined as damage functions. Then:

$G(X)=R(X, d)-S(X, d)$

in which $R$ indicates the structural resistance and $S$ the external action. Both the parameters depend on the damage variable. Therefore, $R$ is the critical damage value, or threshold damage value, provided by the analyst. $S$ is the damage value that is a function of the material properties, structural geometry and loading conditions, which reveal the mechanical structural damage. 
In the present study, the improved lumped damage model determines the damage value as a function of the material properties, structural geometry and loading intensity. Thus, concrete cracking and reinforcements' yielding are accounted. In addition, the extreme value process represents the external loading. Therefore, this approach enables the realistic representation of loading as demonstrated in the next section. When more than one failure mode exist in a structural system, such as observed into hyperstatic structural systems, for instance, the reliability analysis may be performed through the system reliability concept. This approach is not explored in the present study. Nevertheless, the improved lumped damage model may be applied in coupling with the system reliability. In such case, the mechanical model identifies the different collapse paths, which will enables the probability of failure assessment.

\subsection{The loading modelling. The extreme value process}

The service life prescribed by the design codes for usual RC structures is 50 years. Therefore, during a reliability analysis, the assumption of time-constant load on its maximum value over the entire structural service life is unfair. Thus, to represent the loading process in a real form the extreme value process is utilized. To introduce this load-modelling scheme, the cumulative maximum distribution function must be defined. This function for a sampling of $n$ random variables is defined as follows (Cristensen and Baker [29]):

$F_{Y_{n}}(y)=\left[F_{x}(y)\right]^{n}$

in which $F_{x}(y)$ indicates the function of cumulative distribution.

The extreme distribution presented above tends to limiting forms as $n$ becomes higher. These forms are named as asymptotic extreme distribution, which may be classified as: Gumbel, Frechet and Weibull (types I, II e III, respectively), according to the type of the original distribution assumed $F_{x}(y)$ (Beirlant et al. [30]). In the present study, the accidental loading is represented by the Gumbel distribution for maximum, which cumulative probability function is defined as follows (Cristensen and Baker [29]):

$F_{x}(x)=\exp \left[-\exp \left[-\varpi\left(x-u_{n}\right)\right]\right]$

in which $\omega$ represents the form parameter and $u_{n}$ the maximum characteristic value given by Eq. (30). $\mu$ and $\sigma$ indicate the mean and standard deviation, respectively.

$\varpi=\frac{\pi}{\sqrt{6} \sigma} \quad u_{n}=\mu-\frac{0.577216}{\varpi}$

The maximum characteristic of a given extreme distribution is defined as follows:

$F_{x}\left(u_{n}\right)=P\left[\left\{X \leq u_{n}\right\}\right]=1-\frac{1}{n}$

Consequently, the maximum characteristic value for 50 years is known, i.e., such value for the structural service life is defined. Then, the characteristic values for any other time $n$ is achieved by utilizing the Eq. (30) and Eq. (29). Thus, the loading value for a given time step is obtained as follows:

$u_{n}=u_{50}+\ln \left(-\ln \left(\frac{50-n}{50}\right)\right)^{\frac{1}{\omega}}$

\section{Applications}

The proposed coupled approach was applied into the mechanicalprobabilistic analyses of two RC structures: one simple supported beam and one hyperstatic $2 \mathrm{D}$ frame. The limit state function for the reliability problem accounts for the damage values at each inelastic hinge caused by the loading process, solicitation, and the threshold damage value, resistance, as informed in Eq. (33). The threshold damage value adopted in this study is 0.5 , which corresponds to the maximum reparable damage of structures (FlórezLópez et al. [9]).

$G(X)=d_{r e f}-d(X)$

The reliability analyses were performed with mean load increments. Then, the extreme value process determines the loading values at each time step. Therefore, the probability of failure is assessed at each time step accounting for the accumulated damage and the loading history. In addition, the failure scenarios are assessed for each inelastic hinge and the global collapse is determined by the loss of stability, which is also achieved through the improved lumped damage approach. Thus, the mechanical collapse is observed when the equilibrium conditions are no longer observed. i.e. when the efforts distribution leads to the nonequilibrated condition.

Therefore, the system reliability approach was not fully applied in this study. The inelastic hinges are fully dependent. The improved lumped damage model enables the effort distribution during the mechanical-material degradation. Thus, in hyperstatic structures, the failure is observed when the amount of local failures generates a kinematic chain, i.e., a non-equilibrated condition is observed. For all simulations presented in this study, the time for global failure and for the individual failures per hinge is determined.

The strength point of the proposed probabilistic approach is the computational efficiency, in addition to the accuracy. The second application considered in this study, which is a complex mechanical problem, required $1 \times 10^{6}$ simulations. Such analysis spent only 25 hours in a conventional desktop. This performance could be improved by applying high-performance computing techniques, such as OpenMP directives, for instance. This technique could lead the analysis in less than one hour.

\subsection{The simple supported RC beam}

The first application of this study concerns a simple supported RC beam subjected to two concentrated loads, as illustrated in Fig. (5).

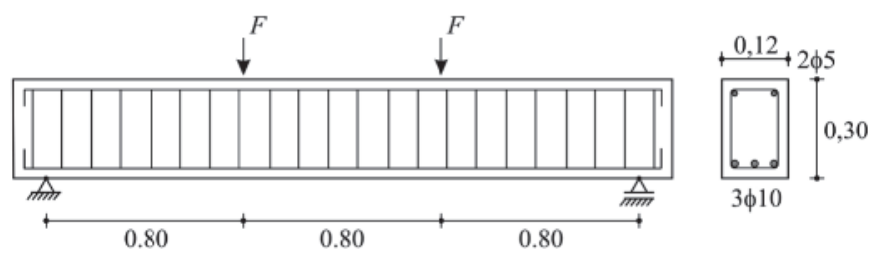

Figure 5

Simple supported RC beam. Dimensions in metre. Reinforcements scheme 
Table 1

Random variables for simple supported RC beam

\begin{tabular}{cccc}
\hline $\begin{array}{c}\text { Random } \\
\text { variable }\end{array}$ & Mean & COV & PDF \\
\hline $\begin{array}{c}\text { Concrete } \\
\text { cover }(\mathrm{cm})\end{array}$ & 1.5 & 0.15 & Normal \\
$\mathrm{f}_{c}(\mathrm{MPa})$ & 38 & 0.10 & Normal \\
$\mathrm{f}_{\mathrm{y}}(\mathrm{MPa})$ & 500 & 0.10 & Lognormal \\
$\mathrm{f}_{\mathrm{su}}(\mathrm{MPa})$ & 550 & 0.10 & Lognormal \\
Load $(\mathrm{kN})$ & 50 & 0.10 & Gumbel-max \\
\hline
\end{tabular}

This beam was experimentally (Alvares [25]) and numerically (Nogueira et al. [26]) analysed in previous researches in the literature. Particularly, Nogueira et al. [26] analysed this beam by the Mazars damage model. The experimental study of Alvares [25] provides the material parameters values, which were considered as the mean value for the random variables during the probabilistic modelling. The coefficient of variation (COV) and the probability density function for such random variables are suggested by Pellizzer et al. [31] and presented in Table (1).

The reinforcements' steel is composed of CA- 50 steel with yielding stress, $f_{\mathrm{y}}$, of $500 \mathrm{MPa}$. The ultimate steel stress, $f_{\mathrm{su}}$, is $550 \mathrm{MPa}$, which corresponded to the $0.8 \%$ strain. The stirrups are $5 \mathrm{~mm}$ diameter, which are separated of $12 \mathrm{~cm}$. The longitudinal reinforcements' bars are $5 \mathrm{~mm}$ and $10 \mathrm{~mm}$ diameter, with concrete cover of $1.5 \mathrm{~cm}$. The incremental-iterative model utilizes $2.0 \mathrm{kN}$ stepsloading at each time step. The Young's modulus and compressive strength for concrete, $f_{c}$, are 29,200 MPa and $38 \mathrm{MPa}$, respectively. The deterministic analysis involving the mechanical behaviour of the beam illustrated in Fig. (5) was carried out before performing the probabilistic modelling. Such procedure aims to illustrate the accuracy and robustness of the improved lumped damage model in representing the mechanical behaviour of $\mathrm{RC}$ structures. For this modelling, the finite element mesh illustrated in Fig. (6) was utilized, which is composed of four finite elements. Such analysis spent only 0.140 seconds in a conventional desktop, with RAM memory of $16 \mathrm{~GB}$ and Intel processor $\mathrm{i} 7-2700 \mathrm{~K}$, which has processing speed of $3.50 \mathrm{GHz}$. The classical lumped damage formulation was utilized as well as the improved formulation proposed in this study. The numerical results of Nogueira et al. [26] were obtained with the Mazars damage model utilizing six finite elements, twenty integration points along the element length and seven integration points along the beam height.

The load-displacement curves for the deterministic analyses are illustrated in Fig. (7).

The Fig. (7) illustrates that both damage approaches, i.e. Lumped and Mazars damage models, were capable for obtaining the mo-

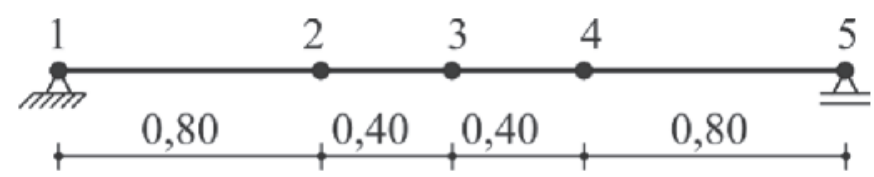

\section{Figure 6}

Finite element mesh simple supported RC beam. Dimensions in metre

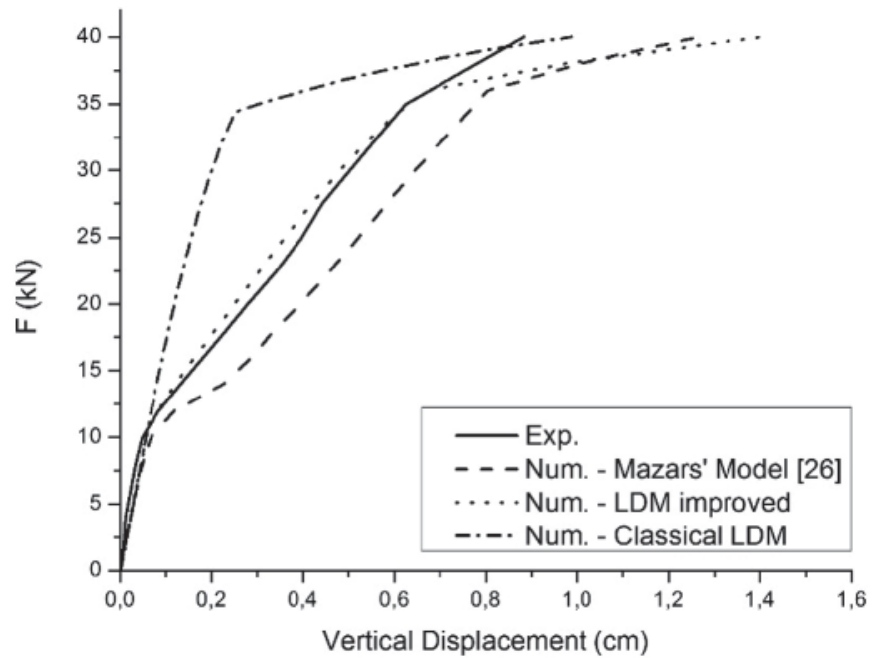

Figure 7

Equilibrium trajectory simple supported RC beam

ments for concrete cracking and reinforcements yielding with adequate accuracy. However, the both damage approaches diverge from the experimental response during the concrete crushing. Such behaviour is expected because the near-collapse conditions is observed in this phase, in which efforts redistribution are limited. It is worth mentioning that the classical lumped damage formulation was not capable for describing accurately the global mechanical behaviour for this beam. This result illustrates the importance of the improvement proposed in this study, which enables the lumped damage approach for representing accurately the distributed mechanical damage cases. In spite of its simplifications, the improved lumped damage formulation demonstrates excellent accuracy, even better than the Mazars model, in representing the global mechanical behaviour.

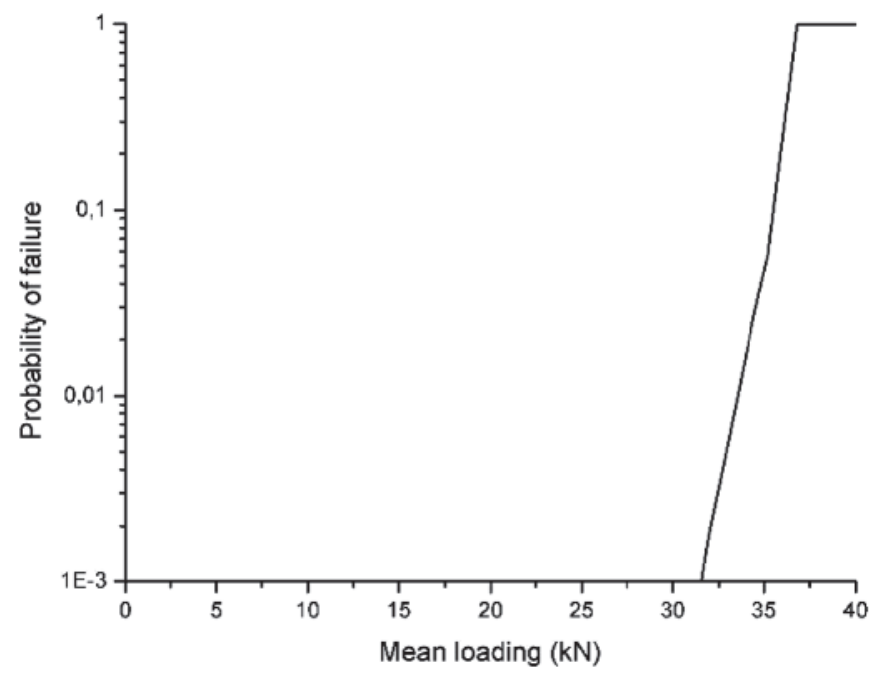

Figure 8

Probability of failure curve for simple supported $\mathrm{RC}$ beam 

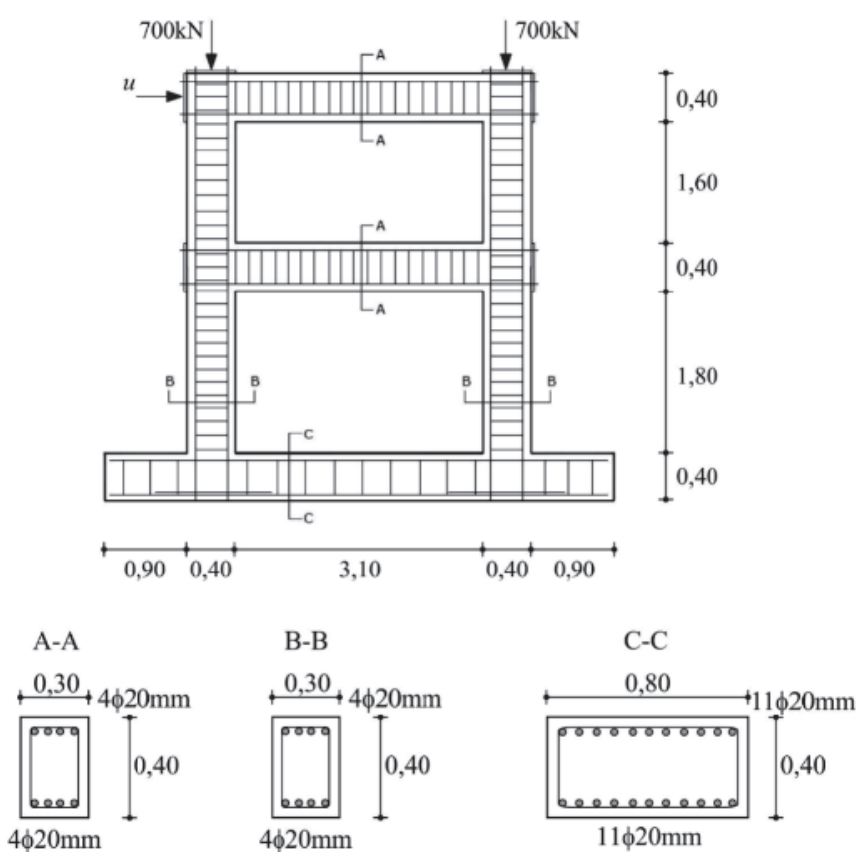

\section{Figure 9}

2D RC frame. Reinforcements' scheme. Vecchio and Collins [27]. Dimensions in metre

The RC beam presented in Fig. (5) was also analysed in the probabilistic context. The random data considered is presented in Table 1. Because this beam is isostatic, only one local failure leads to the mechanical collapse. Moreover, because the middle span region presents the higher strains values, it is expected that the node 3 concentrates the higher values for the probability of failure. The probabilistic analysis consists of imposing loading increments along time. Thus, based on the Monte Carlo simulations, the curve of probability of failure $x$ the mean loading values was obtained, as showed in Fig (8).

The probability of failure reaches high values for loading intensities higher than $32.5 \mathrm{kN}$, as illustrated in Fig. (8). By comparing the results illustrated in Fig (8) with the deterministic analysis shown in Fig (7), one observes that the probability of failure has significantly growth after the bending moment exceeds the plastic moment. The probability of failure achieved for the simple supported RC beam can be compared with reference values. In this study, the reference values are provided by the JCSS [32], which values are described in Table (2). The maximum admissible loading (mean value considering the COV in the Table (1)) is $32 \mathrm{kN}$ for large cost of safety measure and minor consequences of failure. On the

\section{Table 3}

Random variables for 2D RC frame

\begin{tabular}{cccc}
\hline Variable & Mean & COV & PDF \\
\hline $\mathrm{f}_{\mathrm{c}}(\mathrm{MPa})$ & 30 & 0.10 & Normal \\
$\mathrm{f}_{\mathrm{y}}(\mathrm{MPa})$ & 418 & 0.10 & Lognormal \\
$\mathrm{f}_{\mathrm{su}}(\mathrm{MPa})$ & 598 & 0.10 & Lognormal \\
Loading $(\mathrm{kN})$ & 315 & 0.10 & Gumbel-max \\
\hline
\end{tabular}

other hand, for the cost of safety measures and large consequences of failure, the acceptable mean value is $27.2 \mathrm{kN}$. The maximum admissible mean loading, $32 \mathrm{kN}$, is closer to the strain-hardening structural behaviour. Thus, for the isostatic structure, it is advisable adopting moderate or large consequences of failure with the hypothesis of normal or small relative cost of safety measure.

Table 2. Maximum mean loading (in kN) based on JCSS [32]. Simple supported RC beam.

\subsection{The 2D RC frame}

The second application of this study concerns a plane RC frame, which is illustrated in Fig. (9). This structure was experimentally analysed by Vecchio and Collins [27]. The experimental parameters are described in Table (3), which were utilized as the mean values during the probabilistic modelling. The COV was assumed as 0.10 for all the random variables.

The FEM analysis utilizing the improved lumped damage model required only six finite elements for obtaining the accurate results, as shown in Fig. (10). This simpler mesh illustrates the robustness of the lumped damage approach.

The RC frame illustrated in Fig. (9) was initially analysed accounting for the deterministic behaviour. Following the experimental procedures, which were described in Vecchio and Collins [27], the vertical loads of $700 \mathrm{kN}$ were initially applied at the top of the columns' frame. Afterwards, the horizontal load intensity, $u$, was progressively augmented until the mechanical collapse. The equilibrium trajectories for nodes 2 and 3 present good agreement with the experimental response, as illustrated in Fig. (11). The deterministic result illustrates the accuracy of the improved lumped damage model in representing the mechanical collapse of complex RC structures. It is worth mentioning that the proposed mechanical model redistributes automatically the mechanical efforts caused by the

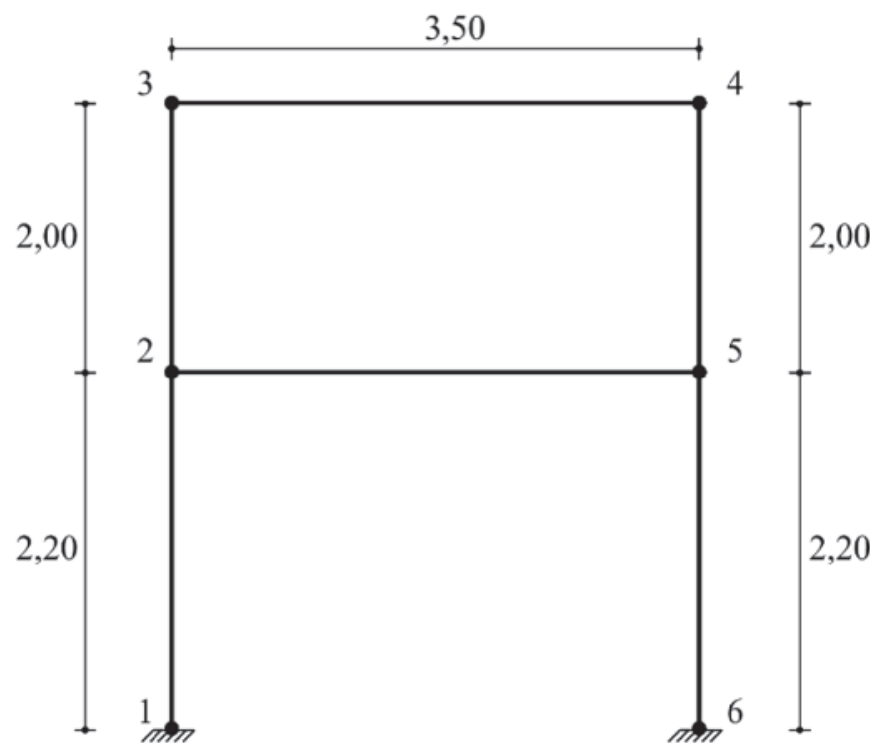

Figure 10

Finite element mesh 2D RC frame.

Dimensions in metre 


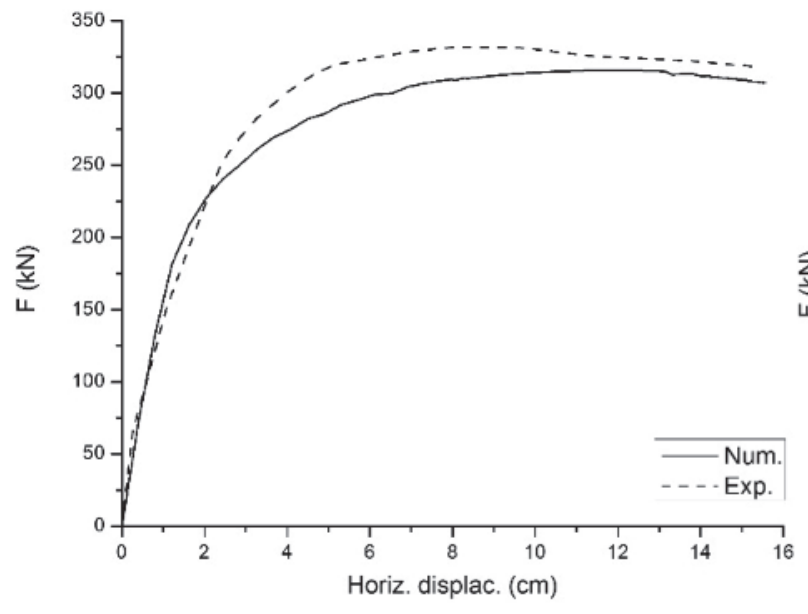

(a)

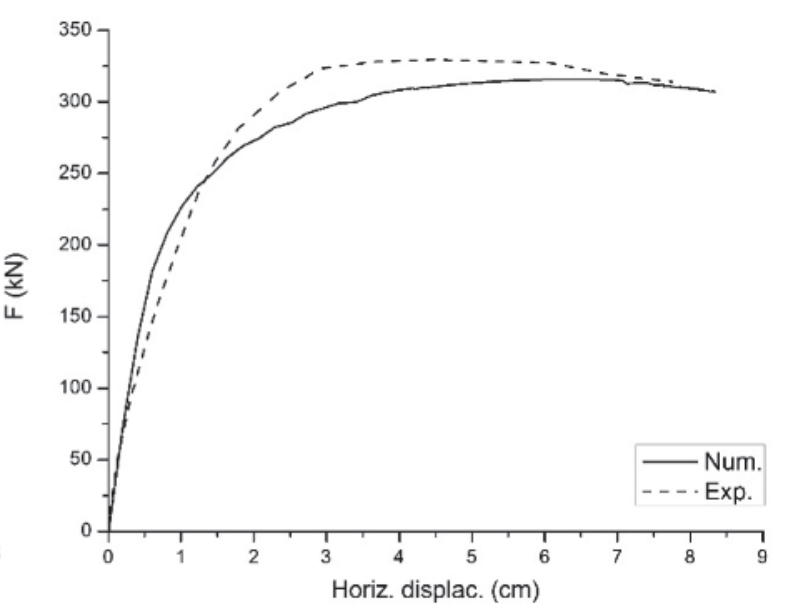

(b)

\section{Figure 11}

Equilibrium trajectory (a) node 3; (b) node 2. 2D RC frame

concrete cracking and the reinforcements' yielding. Thus, this model enables the determination of complex failure scenarios accurately, even in hyperstatic structural systems, which requires the accurate assessment of the mechanical-material collapse path. The damage map is presented in the Fig. (12), which illustrates the damage value for each hinge when the horizontal load is equal to $315 \mathrm{kN}$. According to the Fig. (12), the clamped supports have the higher damage values, followed by the extremities of the two beams.

In the probabilistic modelling, only the horizontal loading was assumed as random, in addition to the material properties. Therefore,

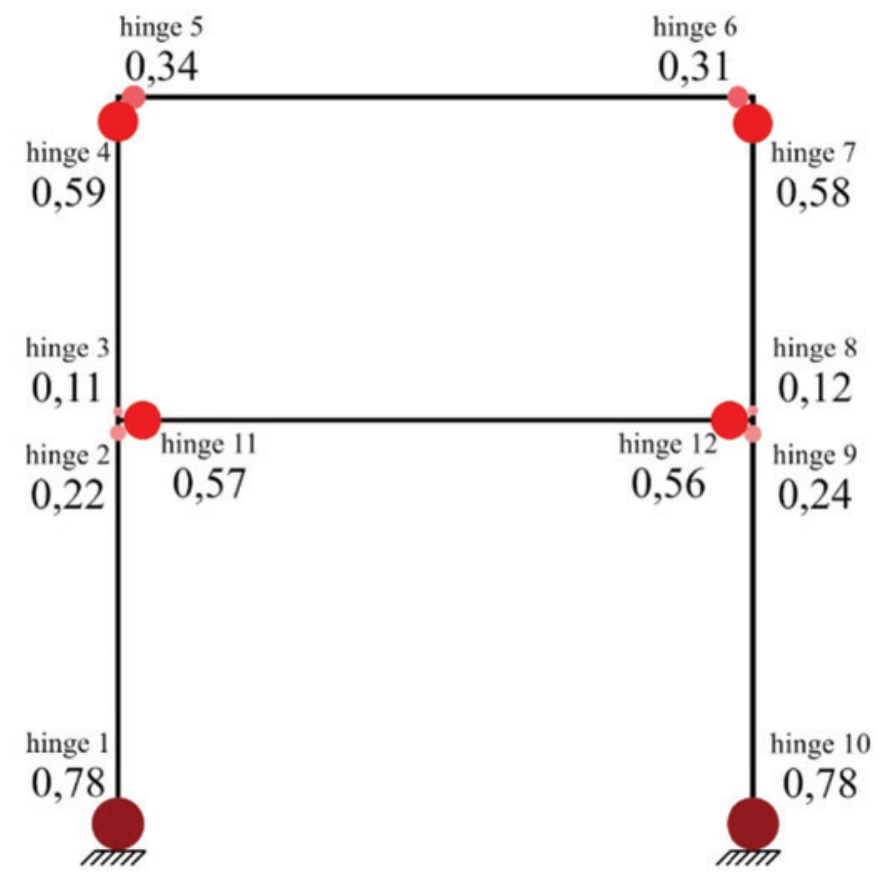

Figure 12

Damage map 2D RC frame the two vertical loads of $700 \mathrm{kN}$ have been applied at the top of the two columns' frame in the deterministic form. Then, the horizontal loading has been applied at the superior end of the first column, until the structure failure. The probabilistic analysis assumed the horizontal load growing from 0 to $350 \mathrm{kN}$. Firstly, the probability of global failure was analysed. The dependence of the probability of failure and the horizontal load value is illustrated in Fig. (13). The values obtained were smaller than the observed in the previous application, because the hyperstatic structures possess structural system redundancy. The maximum probability of failure, 0.497 , occurs for the lateral load of $350 \mathrm{kN}$, as expected.

The critical structural components has major importance during the failure analysis of hyperstatic structural systems. Such information enables the designers and maintenance team to monitoring the structural health. In addition, this information enables the determi-

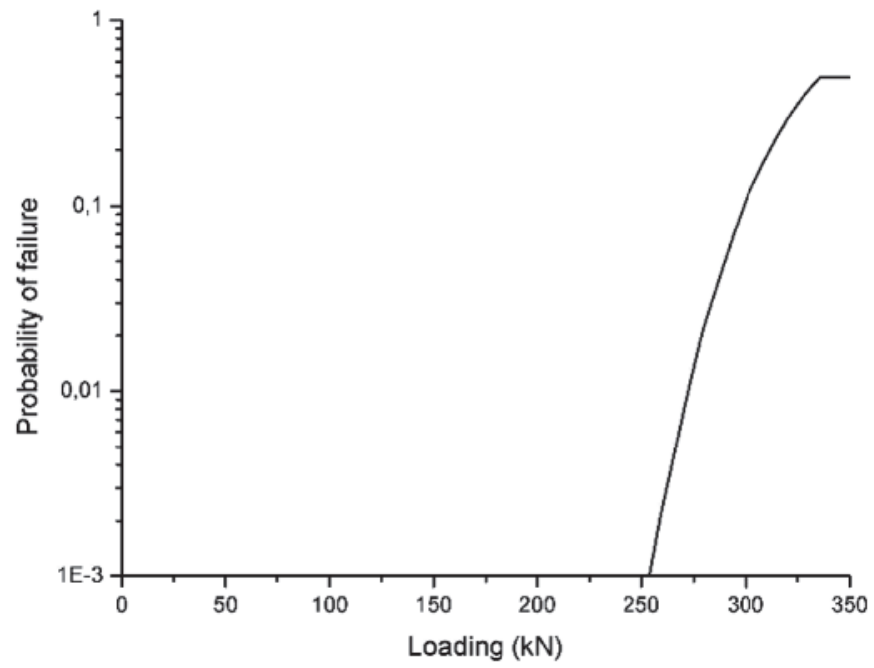

Figure 13

Probability of failure curve for 2D RC frame 

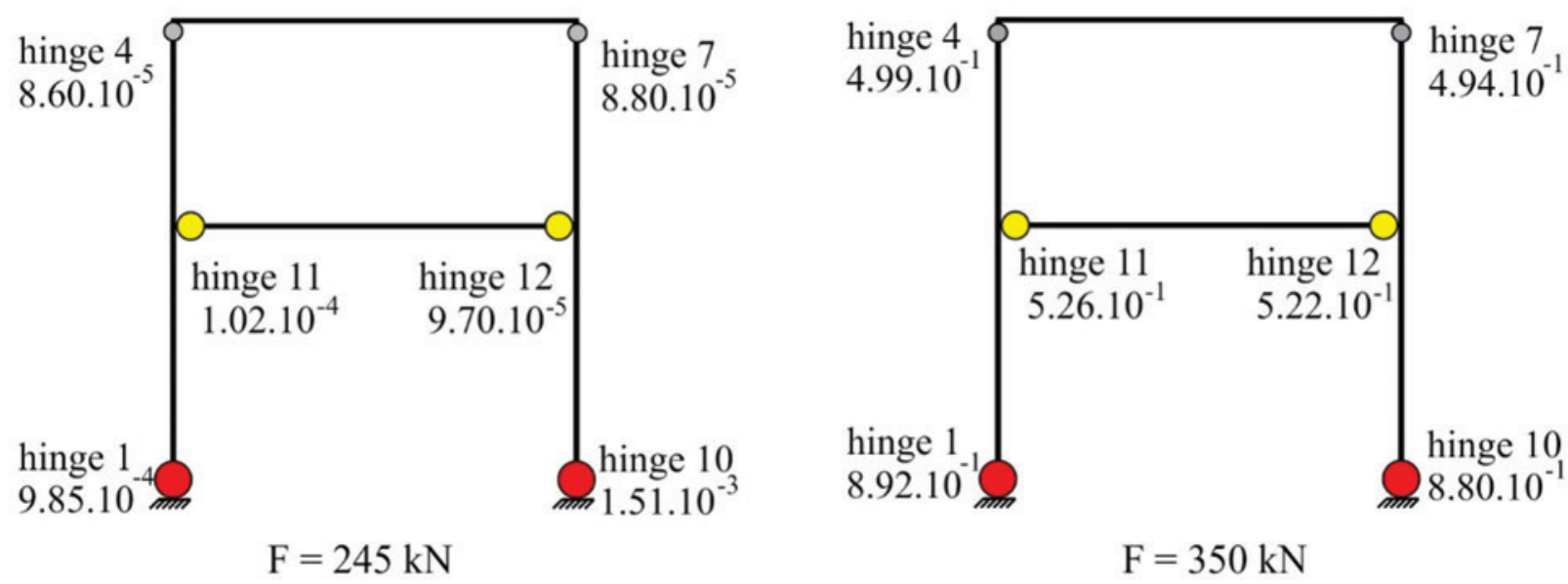

Figure 14

Probability of failure map for 2D RC frame

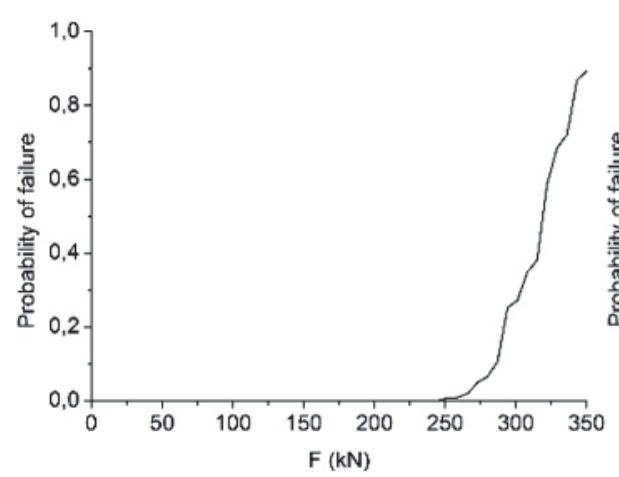

(a)

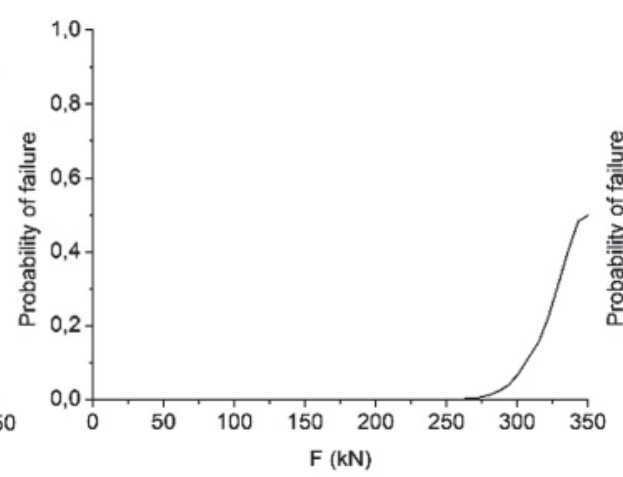

(b)

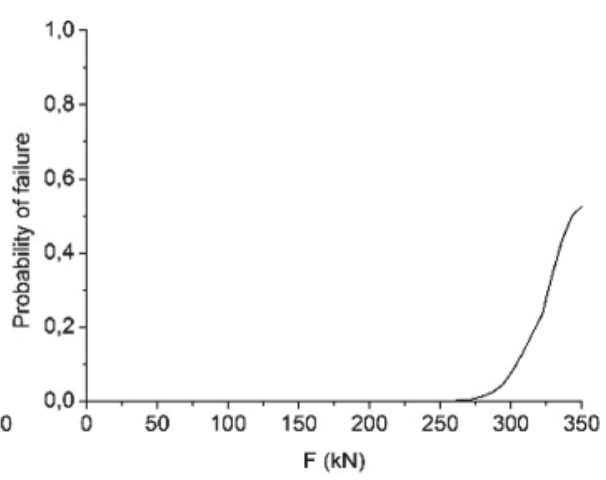

(c)

Figure 15

Individuals probability of failure (a) hinge 1, (b) hinge 4 and (c) hinge 11;2D RC frame

nation of the most probable collapse path. Therefore, the consequences of failure can be predicted, in order to be mitigated. For this reason, the individual probabilities of failure per hinge were analysed. Such result is presented into the failure map, which is illustrated in Fig. (14).

When the horizontal load mean value is $250 \mathrm{kN}$, the individual probabilities of failure are closer to $10^{-4}$. In such scenario, the sequence of failure starts at hinges 10 and 1 , followed by hinges 11 , 12,7 and 4 . On the other hand, for horizontal load mean value of $350 \mathrm{kN}$, the probabilities of failure are higher for all hinges. For this scenario, the collapse is expected to occur in the following sequence of hinges: 1, 10, 11, 12, 4 and 7. The Fig. (15) presents the evolution of the individual probability of failure for hinges 1, 4 and 11 , with the increment of the horizontal load mean value. Analogously to the previous application, the global probability of failure was compared to the JCSS [32] reference values. The Table (4) shows that the maximum acceptable loading (mean value, considering the COV in the Table (3)) is $259 \mathrm{kN}$. In addition, for cost of safety measures and large consequences of failure, the horizontal loading is $217 \mathrm{kN}$. Thus, for the statistical data provided, the individual probability of failure reaches the maximum value of order. The lower load mean value provided by the JCSS [32] causes the damage value of 0.30 into the inelastic hinges at the fixed supports. For this condition, concrete cracking and reinforcements

\section{Table 4}

Maximum mean loading (in kN) based on JCSS [32]. 2D RC frame

\begin{tabular}{cccc}
\hline $\begin{array}{c}\text { Relative cost } \\
\text { of safety measure }\end{array}$ & $\begin{array}{c}\text { Minor consequences } \\
\text { of failure }\end{array}$ & $\begin{array}{c}\text { Moderate consequences } \\
\text { of failure }\end{array}$ & $\begin{array}{c}\text { Large consequences } \\
\text { of failure }\end{array}$ \\
\hline Large & 259 & 252 & 245 \\
Normal & 245 & 231 & 224 \\
Small & 231 & 224 & 217 \\
\hline
\end{tabular}


yielding are expected to occur at those positions. However, because the structure is hyperstatic, the global probability of failure is significantly smaller due to the effort redistribution phenomenon. In addition, this damage intensity enables structural repair as described in Flórez-López et al. [9].

\section{Conclusions}

In this study, the improved version of the lumped damage approach was coupled to the Monte Carlo simulation method for enabling the mechanical-probabilistic modelling of RC structures. The lumped damage model, which considers the damage at the element ends, was improved by the penalization of the cross-sectional inertia in material portions subjected to constant bending moment. This simple assumption improved the mechanical model, which demonstrates to achieve accurate results when compared to experimental and numerical responses available in the literature. In addition, the mechanical modelling enables the determination of damage maps, which are very useful in structural health monitoring.

Because of its computational efficiency, the improved lumped damage model was coupled to the reliability approach without any metamodeling scheme. In spite of the large amount of mechanical model runs required by the Monte Carlo simulation method, the coupled model is reliable. This study suggested a robust algorithm, including stochastic modelling for loading, which join the two methods to provide accurate results in the context of probabilistic analysis. The probabilistic damage map is obtained, which shows the probabilistic damage value at each inelastic hinge.

The probabilistic analysis provides major information of the structural integrity. The global probability of failure has been obtained for each application, as well as the individual probabilities of failure per hinge. Therefore, the algorithm enables the identification of the critical structural components, which is very useful in safety assessment analysis, especially when collapse modelling is accounted.

\section{Acknowledgements}

Sponsorship of this research project by the São Paulo Research Foundation (FAPESP), grant number 2014/18928-2 is greatly appreciated.

\section{References}

[1] Afroughsabet, V.; Biolzi, L.; Ozbakkaloglu, T. High-performance fiber-reinforced concrete: a review. Journal of Materials Science, v. 51, 2016; p.6517-6551.

[2] Carpinteri, A. Post-peak and post-bifurcation analysis of cohesive crack propagation. Engineering Fracture Mechanics, v. 32, 1998; p.265-278.

[3] Oliveira, H.L.; Leonel, E.D. Cohesive crack growth modelling based on an alternative nonlinear BEM formulation. Engineering Fracture Mechanics, v. 111, 2013; p.86-97.

[4] Desmorat, R.; Gatuingt, F.; Ragueneau, F. Local and nonlocal anisotropic damage model for quasi-brittle materials. Engineering Fracture Mechanics, v.74, 2007; p.1539-1560.

[5] Matallah, M.; La Borderie, C. Inelasticity-damage-based model for numerical modelling of concrete cracking. Engineering Fracture Mechanics,76, 2009; p.1087-1108.
[6] Mazars, J. Application de la mechanique de l'endommagement au comportement non lineaire et à la rupture du béton de structure, Paris, Thèse de Doctorat d'État, Université Paris 6, 1984.

[7] Légeron, F.; Paultre, P.; Mazars, J. Damage mechanics modeling of nonlinear seismic behavior of concrete structures. Journal of Structural Engineering, v.131, 2005; p.946-955.

[8] Junior, F.S.; Venturini, W.S. Damage modelling of reinforced concrete beams. Advances in Engineering Software, v.38, 2007; p.538-546.

[9] Flórez-López, J.; Marante, M.E.; Picón, R. Fracture and Damage Mechanics for Structural Engineering of Frames: State-of-the-Art Industrial Applications. IGI Global, 2015.

[10] Cipollina, A.; López-Inojosa, A.; Flórez-López, J. A Simplified damage mechanics approach to nonlinear analysis of frames. Computers \& Structures, v.54, 1995; p.1113-1126.

[11] Flórez-López, J. Frame analysis and continuum damage mechanics. European Journal of Mechanics - A/Solids, 17, 269-283, 1998

[12] Rajasankar, J.; Nagesh, R.; Prasad, A. Modelling inelastic hinges using CDM for nonlinear analysis of reinforced concrete frame structures. Computers and Concrete, v.6, 2009; p.319-341.

[13] Alva, G.M.S.; El Debs, A.L.H.C. Application of lumped dissipation model in nonlinear analysis of reinforced concrete structures. Engineering Structures, v.32, 2010; p.974-981.

[14] Marante, M.E.; Flórez-López, J. Three-dimensional analysis of reinforced concrete frames based on lumped damage mechanics. International Journal of Solids and Structures, v.40, 2003; p.5109-5123.

[15] Amorim, D.L.D.F.; Proença, S.P.; Flórez-López, J. Simplified modeling of cracking in concrete: Application in tunnel linings. Engineering Structures, v.70, 2014; p.23-35.

[16] Febres, R.; Inglessis, P.; Flórez-López, J. Modeling of local buckling in tubular steel frames subjected to cyclic loading. Computers \& Structures, v.81, 2003; p.2237-2247.

[17] Nowak, A.S; Collins, K.R. Reliability of structures, McGraw Hill, Michigan, 2000.

[18] Sankararaman, S. Uncertainty Quantification in Remaining Useful Life Prediction Using First-Order Reliability Methods. IEEE Transactions on Reliability, v.63, 2014; p.603-619.

[19] Sun, B.; Zeng, S.; Kang, R.; Pecht, M.G. Benefits and challenges of system prognostics. IEEE Transactions on Reliability, v.61, 2012; p.323-335.

[20] Straub, D. Value of information analysis with structural reliability method. Structural Safety, v.49, 2014; p.75-85.

[21] Liberati, E.A.P.; Nogueira, C.G.; Leonel, E.D.; Chateauneuf, A. Nonlinear formulation based on FEM, Mazars damage criterion and Fick's law applied to failure assessment of reinforced concrete structures subjected to chloride ingress and reinforcements corrosion. Engineering Failure Analysis, v.46, 2014; p.247-268.

[22] Leonel, E.D.; Chateauneuf, A.; Venturini, W.S. Probabilistic crack growth analyses using a boundary element model: Applications in linear elastic fracture and fatigue problems. Engineering Analysis with Boundary Elements, v.36, 2012; p.944-959. 
[23] Frangopol, D.M.; Ide, Y.; Spacone, E.; Iwaki, I. A new look at reliability of reinforced concrete columns. Journal of Structural Safety, v.2, 1996; p.123-150.

[24] Neves, R.A.; Chateauneuf, A.; Venturini, W.S. Component and system reliability analysis of nonlinear reinforced concrete grids with multiple failure modes, Structural Safety, v.30, 2008; p.183-199.

[25] Alvares, M. S. The study of the damage model for concrete: formulation, parametric identification and finite element method applications. $\mathrm{PhD}$ thesis (in portuguese). University of São Paulo, 1993.

[26] Nogueira, C.G.; Venturini, W.S.; Coda, H.B. Material and geometric nonlinear analysis of reinforced concrete frame structures considering the influence of shear strength complementary mechanisms. Latin American Journal of Solids and Structures, v.10, 2013; p.953-980.

[27] Vecchio, F.J.; Collins, M.P. The modified compression-field theory for reinforced concrete elements subjected to shear. ACI Structural Journal, v.83, 1986; p.219-231.

[28] ACl Committee 318, 2008, "Building Code Requirements for Structural Concrete ( $\mathrm{ACl}$ 318-99) and Commentary (318R-08)," American Concrete Institute, Farmington Hills.

[29] Cristensen, P.T.; Baker, M. J. Structural reliability theory and its applications, Berlim: Springer Science \& Business Media, 2012.

[30] Beirlant, J.; Goegebeur, Y.; Segers, J.; Teugels, J. Statistics of extremes: theory and applications. West Sussex: John Wiley \& Sons, 2006.

[31] Pellizzer, G. P.; Leonel, E. D.; Nogueira, C. G. Influence of reinforcement's corrosion into hyperstatic reinforced concrete beams: a probabilistic failure scenarios analysis. IBRACON Structures and Materials Journal, v. 8, 2015; p.479-490.

[32] Diamantidis, D., ed. Report 32: Probabilistic Assessment of Existing Structures-A publication for the Joint Committee on Structural Safety (JCSS). Vol. 32. RILEM publications, 2001. 